\section{RUÍNA E RECONSTRUÇÃO: AIDS E DROGAS INJETÁVEIS NA CENA CONTEMPORÂNEA}

\section{Francisco Inácio Bastos}

Rio de Janeiro, Relume-Dumará-ABIA/IMS/UERJ, 1996. 242 p.

Poderia ser apenas uma coleção de artigos, mas é verdadeiramente um livro; poderia ser apenas mais um livro, mas também é muito mais que isso: Ruina e reconstrução: Aids $e$ drogas injetáveis na cena contemporânea, de Francisco Inácio Bastos, é uma obra inteira, viva, e um trabalho fundamental da (e para a) saúcle coletiva.

O texto de Bastos tem a qualidade, tão rara quanto cada vez mais imprescindível, de tratar da especificidade de uma das áreas prioritárias da ação médico-sanitária na atualidade - a epidemia da Aids neste âmbito, a exposição pelo uso de drogas injetáveis - sem perder de vista o horizonte mais abrangente em que a mesma está inserida como problema prático e desafio teórico. De fato, a amplitude temática, pluralidade metodológica e rigor analítico com que o autor trata seu objeto dificilmente caminham juntos na literatura mais freqüente sobre o assunto. Ao mesmo tempo, encontrase nesse livro um exemplo concreto de como o diálogo entre conhecimento positivo e reflexão crítica, entre método qualitativo e quantitativo, entre campos disciplinares diversos, assim como entre os diferentes sujeitos desses campos, destinatários tanto quanto agentes das ações de saúde, pode se constituir num caminho fecundo para a conciliação de ciência e humanismo, competência técnica e respeito ao outro, resultados práticos e democracia.

O elemento nuclear a estruturar todo o traballho de conhecimento e reflexão desenvolvido e sistematizado por Bastos é a decidida e fundamentada defesa da estratégia de redução de danos dos expostos pelo uso de drogas injetáveis (UDIs) à infecção eadoecimento pelo HIV, o vírus causador da Síndrome da Imunodeficiência Adquirida, ou Aids. Quando tratamos de tema tão fortemente polêmico, é comum colocarmo-nos diante dele de uma forma extremada, ora com um pessimismo paralisante, ora com um messianismo onipotente. A questão das drogas em nossas sociedades ocidentais contemporâneas não foge à regra. Tão envolvida está em mitos, tabus culturais, estratégias biopolíticas, estruturas sócio-econômicas, que é difícil tratarmos de qualquer aspecto relacionado ao uso de drogas, por mais 'técnico' que nos pareça, sem tender a um certo 'fervor' militante.

Nada contra o fervor, nem tampouco a militância, indispensáveis ambos. O problema é que esses elementos podem nos deixar pouco espaço para a reflexão e o verdadeiro diálogo, levando-nos à defesa a priori de diagnósticos e soluções, tributárias às vezes dos mesmos mitos, tabus, estratégias e estruturas que pretendemos superar. Fechamo-nos, nesse caso, para um enfrentamento adequado e socialmente legítimo dos problemas tratados. Dados empíricos e argumentos são chamados a trazer um testemunho definitivo, e evocados para "fechar a questão". Na prática cotidiana da produção de conhecimento e proposição de intervenções, no entanto, essa circularidade que se estabelece entre juízo e fundamento acaba por se auto-esterilizar, minando, com seu fervor, a fecundidade militante do argumento.

Bastos não está desatento a este risco. Ele reconhece-o na pobre alternativa entre inércia e fatalismo que domina os estudos e as propostas que se debruçam sobre a complexidade $\mathrm{e}$ dificuldade de deter a epidemia da Aids entre UDIs. De um lado, o imobilismo que resulta da aposta "distópica" (p. 191) em um mundo sem drogas como única solução possível para o problema - condição improvável tanto quanto prescindivel, se não mesmo indesejável. De outro lado (ou do outro lado da mesma moeda), um 'realismo' que acaba por tratar a Aids como um 'sobredano' inevitável do uso de drogas injetáveis, resultando numa atitude conformista e derrotista. É justamente nas aberturas que oferece para escapar à esterilidade dessas posições unilateralizadas que Bastos enxerga os maiores méritos da estratégia de redução de danos, seja como alternativa tecnopolítica para o controle da epidemia de HIV/Aids, seja como um compromisso conseqüente com a qualidade de vida daqueles que, por qualquer razão, estejam fazendo uso de substâncias psicoativas: "Porque minimizar os danos decorrentes de uma dada conduta", diz o autor, "é, em primeiro lugar, 
admitir que ela existe, o que significa falha do sistema repressivo, mas também falha relativa da abordagem preventivo-educativa. Significa também admitir que o usuário pode não demandar tratamento médico-psicológico, mas apenas meios de persistir nas suas práticas de modo mais seguro. $\mathrm{E}$ isso significa confrontar os terapeutas com a irreclutibilidade dos desejos e condutas do outro. $O$ novo paradigma no campo do abuso de drogas (Stimson, 1990), o conceito de redução de danos", prossegue Bastos, "implica conviver com as limitações de nossa terapêutica e nossas políticas sociais, mas situar-se no campo oposto ao da inércia e do fatalismo" (p. 154).

Portanto, ao privilegiar a estratégia de redução de danos como paradigma de enfrentamento da questão drogas-Aids, Bastos, muito mais que adotar um modelo de intervenção, está elegendo um eixo simultaneamente axiológico, epistemológico e tecnológico para pensar/conhecer/transformar seu objeto de cuidado. Tal eleição implica um resoluto (e sempre difícil) abandono de certezas, tanto de saída quanto de chegada. Em relação a estas últimas, isso equivale a assumir que não podemos fixar de antemão a melhor conduta para o outro, o outro que usa droga injetável, o outro exposto ao HIV. A única certeza que parece válicla a Bastos, nesse sentido, é a de que "só desconstruindo a metáfora, tanto pregnante como vazia, da droga como objetivação do mal e do usuário como sua encamação, poderemos proceder a uma topografia dos eventuais danos advindos dessa prática e pensar as difíceis alternativas individuais e coletivas necessárias à sua redução ou minimização" (p. 187).

Mas não são apenas as finalidades do trabalho que precisam ser sacudidas de suas "confortáveis" certezas. A desconstrução da "maldição das drogas" impõe também rever as verdades contidas no instrumental teórico e metodológico que a podem sustentar, a começar pelo próprio arsenal científico desenvolvido pelas ciências da saúde, especialmente a epidemiologia. E aqui Bastos não está menos atento às polarizações estéreis: "Revisitando o paradigma do sexo (mais) seguro, Hart (1993) aponta para as tensões encerradas na definição epidemiológica - mais estreita de risco, conceito, no entanto, absolutamente central à disciplina. Impõe-se a necessidade de situar essa definição e atribuição de riscos de acordo com os contextos singulares em que têm lugar as situações que os determinam. Deixar de lado os conhecimentos trabalhosamente obticlos ao longo de uma década de pesquisa acerca da determinação e mensuração de riscos, em prol da procura de uma singularidade absoluta é apostar numa desconstrução estéril e, mais do que isso, perigosa. Assim, o uso de preservativos nas interações sexuais de um modo geral, ou a disponibilidade/provisão de seringas e agulhas novas para usuários ativos são marcos fundamentais das diversas iniciativas preventivas. Por outro lado, reificar conclusões de estudos, sejam eles quantitativos ou qualitativos, enquanto definição acabada de histórias 'naturais' da infecção/ doença é cair no outro extremo, tão ingênuo, ineficaz e perigoso como o anterior" (pp. 144-5).

Graças a essa dupla recusa, Bastos credenciase a uma ampla visita às diversas fontes disponiveis de conhecimento, inventariando-as exaustivamente e apropriando-se delas com critério, ora justapondoas, ora contrapondo-as, aqui recorrendo às suas contribuições positivas, ali denunciando limites, fragilidades e desafios. Ganha, com isso, o tratamento teórico da questão, que, conforme apontam Richard Parker e Jane Galvão em seu 'Prefácio', recebe das mãos clesse autor "uma das mais completas análises" já realizadas a respeito. $\mathrm{E}$ ainda, comoum ganho suplementar mas não menos relevante, nós, seus leitores, passamos a dispor de uma valiosa sistematização do "estado da arte" na produção de conhecimentos para o diagnóstico e intervenção em saúde coletiva. Aos tradicionais recortes epidemiológicos $\mathrm{e}$ categorias sanitárias, Bastos faz juntar-se o testemunho de novos conceitos, como o de vulnerabilidade, tal como desenvolvido por Mann e cols., o uso de novas tecnologias, como o geoprocessamento, e o recurso a metodologias de pesquisa relativamente estranhas ao campo da saúde até tempos recentes, como a etnometodologia.

De posse do mais rico instrumental teóricometodológico e de uma visão menos cristalizada de suas contribuições, somos levados a abandonar, de modo fundamentado e consistente, velhos mitos e tabus, perpetuadores de preconceitos $\mathrm{e}$ equívocos. Um exemplo é a pretensão de explicar a prevalência do uso de drogas como questão comportamental sem compreender sua dimensão 
econômica. Com efeito, o mapeamento da produção e circulação da droga pode trazer-nos mais subsídios práticos do que cuicladosas análises psico-emocionais dos consumidores, como no caso da associação entre o aumento do uso de drogas no interior de São Paulo e o 'estouro' de outras vias de escoamento de sua produção na América Latina. Por outro lado, considerar as mediações culturais que relacionam a economia da droga e o comportamento do usuário pode, por vezes, tornar-se imprescindivel para compreender a dinâmica drogas-Aids, como no caso do Rio de Janeiro, onde, apesar da propalada atividade de tráfico, o padrão de uso de drogas injetáveis faz com que essa categoria de exposição ao HIV/Aids tenha peso relativamente pequeno em relação a outros centros urbanos. Outro exemplo, ainda, é a derrubada do mito "mercadológico" de que a diminuição da disponibilidade acarreta sempre diminuição de consumo de drogas e, por conseqüência, de seus danos. Na verdade, a pressão sobre a oferta em algumas situações só faz deslocar o consumo para padrões mais danosos de uso e, pior, menos conhecidos.

Mas não é só no momento do diagnóstico que o conjunto de informações e análises desenvolvidas e/ou recompiladas por Bastos traz contribuições positivas. Alternativas de intervenção são examinadas com o mesmo cuidado e produtividade. Entre estas, e por falta de mais espaço, eu destacaria pelo menos três sugestões que me parecem de especial importância e com as quais gostaria de finalizar essa resenha: 1) a aposta em redes informais de "disseminação" de informação para propiciar comportamentos auto e interprotetores entre UDIs, rastreadas a partir das próprias redes de disseminação da infecção; 2) o investimento em organizações políticas e de auto-ajuda que se ocupem ativamente da questão drogas-Aids mas constituída de forma pluralista em sua composição e propósitos, dadas as dificuldades para formações associativas estritamente construídas com base na experiência do consumo de drogas; e 3) o estabelecimento de estratégias diferenciadas para subgrupos diversos de UDIs, conhecendo seus característicos "limiares de aderência" e não cleixando de fazer "o possivel" para aqueles que se encontram em cada um desses limiares.
Bem, agora é com o leitor, de quem não desejo roubar mais do prazer intelectual e do estímulo à ação resultantes da 'descoberta' de Ruina e reconstrução. Não resisto, contudo, a encerrar a resenha sem citar uma máxima de Bachelard, que me parece a síntese da argumentação de Bastos e o sentido mais forte da provocação que nos faz: "De acordo com nossa coragem ou nossa fadiga nós diremos que o mundo está começado ou que ele está inacabaclo."

\section{José Ricardo de Carvalho Mesquita Ayres Professor do Departamento de Medicina da Faculdade de Medicina cla USP 05021-001 São Paulo - SP \\ O BRASIL E A QUESTÃO JUDAICA: IMIGRAÇÃO, DIPLOMACIA E PRECONCEITO} Preventiva Rua Cutoaxu, 799/54

Jeffrey Lesser

Rio de Janeiro, Imago, 1995. 372 p.

As sociedades conformam determinadas noções através das quais se identificam, reconhecem-se e são reconhecidas, conferem sentido e legitimidade a si mesmas, às suas estruturas, às suas instituições, às práticas e às relações dos indivíduos que as compõem. O processo de imposição e de generalização, de produção da adesão a essas noções, é concomitante ao de sua naturalização, isto é, de negação do seu caráter histórico e social. É como crenças, portanto, que elas se afirmam e operam, orientando as percepções e as ações dos indivíduos.

O que têm feito as ciências sociais, em boa medida, é relativizar algumas dessas noções, desencantá-las restituindo seus vínculos históricos, remetendo-as aos espaços e às relações sociais a partir dos quais são produzidas e que, ao mesmo tempo, contribuem para produzir. $\hat{E}$ preciso reconhecer, entretanto, que nem sempre este exercício de relativização se mostra possível, incorporando também o cientista social noções impostas que, desse modo, terminam por se constituir em 